\title{
The Hardening of Fe-Mo Single Crystals by Non-Deforming Precipitated Particles
}

\author{
By Toshihiro Yamagata*, Kohei Yagisawa* \\ and Hidehiko Yoshida*
}

\begin{abstract}
Single crystals of iron base molybdenum alloys containing a high volume fraction of precipitated particles $\mathrm{Fe}_{2} \mathrm{M}$ o noncoherent with the matrix were extended at various temperatures between $-110^{\circ}$ and $200^{\circ} \mathrm{C}$. Critical resolved shear stresses in these single crystals depended on the particle size, mean interparticle spacing, and deformation temperature, but not on the crystal orientation of the single crystals used. The increment of the macroscopic yield stresses by the precipitated particles was obtained by subtracting the solid solution strengthening of the matrix from the observed yield stresses in the aged specimens. It was found that the stress increment by the noncoherently precipitated particles was explained fairly well by the Orowan's mechanism in this alloy system. At the initial stage of plastic deformation, neither primary nor cross slip lines could be resolved by replica-electron microscopy. On the other hand, at a large strain of about 8\%, cross slips were clearly observed to take place over a distance of the order of particle size. The changes in crystal orientation with extension were barely perceptible in the over-aged Fe-10\%Mo alloys, probably less than 1 degree even after 10\% elongation. The increases in flow stress due to work hardening seemed to be rather independent of the crystal orientation of aged specimens and deformation temperature. This can better be described in terms of a secondary slip theory by Ashby than a model proposed by Fisher et al..
\end{abstract}

(Received August 22, 1968)

\section{Introduction}

The precipitation hardening is now understood to be due to the long or short range interaction between glide dislocations and precipitated particles. In some cases the hardening is caused by the resistance by which the dislocation motion is stemmed during the shearing of the particles coherent with the matrix. In other cases the particles are non-coherent with the matrix, so that the dislocations cannot penetrate the particles and an additional stress is needed to bow out the dislocations between the particles. The hardening by the latter mechanism in a bcc alloy has been investigated in the present work.

Recently, it is believed that the critical resolved shear stress in fcc alloys containing non-deformable particles are governed by Orowan's mechanism. In order to test Orowan's theory, the following points should be carefully considered in conducting an investigation. Firstly, single crystals must be used to eliminate the effect of grain boundary precipitation and to obtain a uniform distribution of the precipitated particles. Secondly, the yield stress must be measured at a small plastic strain, because the rate of work hardening in the initial stage of deformation is very high. Thirdly, the critical interparticle spacing, to which the macroscopic yield stress corresponds, must be correctly evaluated. Fourthly, the strengthening of the matrix depleted in solute atoms should be estimated.

Although numerous works on the hardening by nondeformable particles have been already published, only a few reports are avaialble on the single crystals. Among them, Dew-Hughes and Robertson ${ }^{(1)}$ measured

* National Research Institute for Metals, Tokyo, Japan.

(1) D. Dew-Hughes and W. D. Robertson : Acta Met., 8 (1960), 147. critical resolved shear stresses in single crystals of Al$1.3 \sim 2.2$ at\% $\mathrm{Cu}$ alloys in the over-aged state. In this case the composition of $\mathrm{Cu}$ in the matrix was retained constant, but the volume fraction of the equilibrium $\theta$ phase was changed. In spite of the irregular shapes of the $\theta$ particles, Ashby's recal-

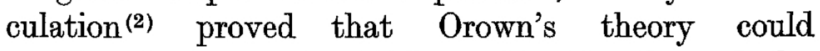
explain their results fairly well: In the calculation Ashby assumed a random distribution of $\theta$ particles and employed the result of evaluation by Labusch for the mean planar interparticle spacing between the nearest neighbours. Then, he replotted the initial shear stress, $\tau_{p}$, caused by particles as a function of mean planar interparticle spacing and of the line tension of dislocations calculated by Nabarro. The slope of the -linearity thus obtained was in good agreement with a theoretical value by the Orowan's theory. Furthermore, Ashby et al. ${ }^{(3)(4)}$ investigated also the hardening mechanism in $\mathrm{Cu}$ single crystals, all of which had the same crystal orientation and contained dispersed spherical particles $\mathrm{SiO}_{2}$. He discussed, in that work, the way of calculating the mean particle size and interparticle spacing, and found out that the hardening due to the particles was inversely proportional to the mean interparticle spacing calculated by his method.

On the other hand, as to the work hardening in the alloys containing hard dispersed particles a few theories have been proposed. According to Fisher et al. (5), the increment of strain hardening is due to dislocation loops left around the particles in the slip plane by

(2) M. F. Ashby : Z. Metallk., 55 (1964), 5.

(3) R. Ebeling and M. F. Ashby: Phil. Mag., 13 (1966), 805.

(4) M. F. Ashby and R. Ebeling : Trans. AIME, 236 (1966), 1396.

(5) J. C. Fisher, E. W. Hart, and R. H. Pry : Acta Met., 1 (1953), 336. 
Table 1 Impurity contents contained in tensile specimens

\begin{tabular}{c|c|c|c|c|c|c|c|c}
\hline \hline $\mathrm{C}$ & $\mathrm{Si}$ & $\mathrm{Mn}$ & $\mathrm{P}$ & $\mathrm{S}$ & $\mathrm{Al}$ & $\mathrm{Cu}$ & $\mathrm{O}$ & $\mathrm{N}$ \\
\hline 0.003 & 0.007 & N.D. & $<0.001$ & 0.003 & 0.003 & 0.019 & 0.008 & 0.001 \\
\hline
\end{tabular}

Orowan's mechanism. They described the increment of flow stress in terms of the volume fraction of particles, the number of concentric loops around each particle and the particle size. Dew-Huches et al. examined this theory on Al-Cu alloys containing $\theta$ precipitates and concluded that the work hardening of this alloy system is well interpreted by the mechanism of Fisher et al.. Other authors, however, pointed out inconsistencies with this theory. Later, Ebeling et al.(3) investigated the work hardening of $\mathrm{Cu}$ single crystals containing the particles that were produced by an internal oxidization method. In order to explain these results, Ashby(6) developed a theory based on the secondary slips visualized as prismatic loops and their interactions with primary glide dislocations.

Very little has been known on the hardening by nondeformable precipitated particles in bcc alloys. The present authors ${ }^{(7)(8)}$ previously reported the precipitation behaviors and mechanical properties in polycrystals of iron-molybdenum binary alloys. According to their results, below $900^{\circ} \mathrm{C}$ a Laves phase with the $\mathrm{Fe}_{2} \mathrm{~W}$ structure precipitated as a final equilibrium phase. Besides, Marcus et al.(9) identified the precipitated phase in Fe-Mo alloy with the Laves phase of the $\mathrm{Fe}_{2} \mathrm{Mo}$ structure by the Mössbauer method. Single crystals of iron-molybdenum alloys with definite crystal orientations were used as tensile specimens in the present experiment. In iron and iron alloys it is generally believed that the dislocation cross slips take place much more easily even at the initial stage of plastic deformation than in fcc alloys. The present work was carried out to investigate whether Orowan's theory is still valid in this alloy system and which theory on work hardening is more appropriate to explain the experimental results.

\section{Experimental}

The specimens used were iron base binary alloys containing 3, 5, 7 and $10 \mathrm{wt} \%$ molybdenum. Both 7 and 10 wt\% molybdenum alloys were used for the measurements of precipitation hardening, and solution hardening of the matrix in the over-aged specimens was estimated from the yield stresses observed in 3 and 5 wt\% molybdenum alloys. Alloys with specific compositions were prepared by melting electrolytic iron and $99.99 \%$ molybdenum in an induction furnace under a hydrogen atmosphere of $100 \mathrm{mmHg}$. The

(6) M. F. Ashby : Phil. Mag., 14 (1966), 1157.

(7) K. Yagisawa and H. Fujita : Japan J. Appl. Phys., 6 (1967), 826.

(8) T. Yamagata, K. Yagisawa and H. Yoshida : Proceeding of the memorial lecture meeting on the 10th anniversary NRIM, (1966), p. 98.

(9) H. L. Marcus, M. F. Fine and L. H. Schwartz : J. Appl. Phys., 38 (1967), 4750. ingots of these alloys were then forged and rolled to the sheets of $1.2 \mathrm{~mm}$ thickness.

Since, except $3 \%$ molybdenum alloy, the preparation of large single crystals by the ordinary strain-anneal technique was extremely difficult, only coarse grains $1 \sim 2 \mathrm{~cm}$ in size were grown in $30 \mathrm{~cm} \times 4 \mathrm{~cm} \times 0.12 \mathrm{~cm}$ cold-rolled sheets by the following procedures. These large sheets were first annealed at $1200^{\circ} \mathrm{C}$ to obtain grains about a few $\mathrm{mm}$ in diameter, then extended 3 to $5 \%$, and finally heated at $1300^{\circ} \mathrm{C}$ in hydrogen atmosphere for several hours. The tensile specimens with desired crystal orientations were selected from these coarse grains. Fig. 1 shows three groups of tensile axes of the specimens investigated in the present study. The result of chemical analysis for the tensile specimens is given in Table 1 . The size of the tensile specimens was $40 \mathrm{~mm}$ in whole length, $5 \mathrm{~mm}$ in length of the parallel gauge parts, $3 \mathrm{~mm}$ in width, and 0.8 to $1 \mathrm{~mm}$ in thickness. After shaping and polishing by emery paper, the specimens were homogenized at $1100^{\circ} \mathrm{C}$ in argon atmosphere of 99.999\% purity for 3 hours and then quenched into water at room temperature. Aging treatments were carried out at $700^{\circ} \mathrm{C}$ in an evacuated quartz tube, 40 hours for 10\% Mo and 330 hours for 7\% Mo alloys, to obtain the over-aged state of equilibrium.

The specimens were extended with an Instron type tensile machine at a strain rate of $3 \times 10^{-4} \mathrm{sec}^{-1}$ at various temperatures between $-110^{\circ} \mathrm{C}$ and $200^{\circ} \mathrm{C}$. The aged specimens did not show obvious yield stresses because of the high work hardening rates in the initial stage of plastic deformation. In this experiment, therefore, the stress at which the stress-strain relationship begins to deviate from the apparent elastic region was adopted as the yield stress. The amounts of strain at that stress was measured to be about $5 \times$

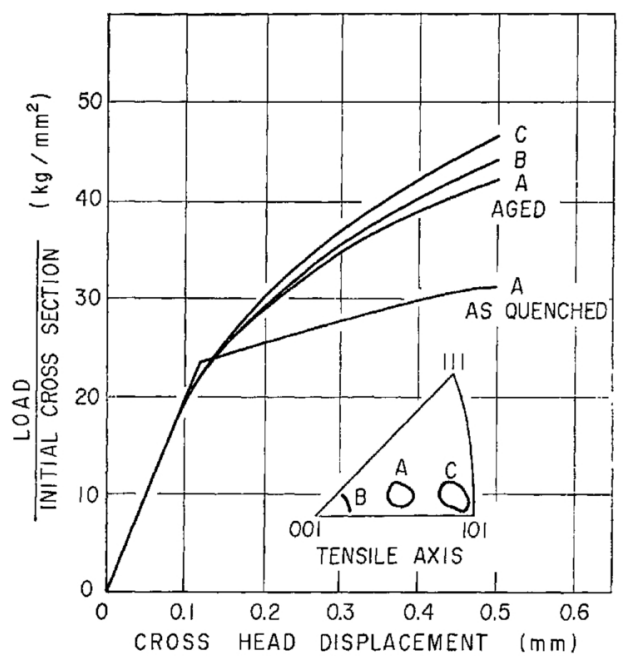

Fig. 1 Tensile axes of single crystal specimens and istress versus cross-head displacement curves obtained at room temperature in the $\mathrm{Fe}-10 \%$ Mo alloy 
$10^{-4}$ by a foil strain gauge stuck on the specimen surface. The rotation of tensile axis with straining was checked by a back reflection Laue method at an interval of $2 \%$ elongation until the total elongation reached $10 \%$. The variation in lattice parameter with the molybdenum content was measured by the X-ray (211) diffraction line using the as-quenched polycrystalline specimens with various amounts of molybdenum. Molybdenum contents in the matrix of the single crystals after aging were estimated from the measurements of the lattice parameter by filing the aged specimens and annealing the filed powders for 10 hours at $500^{\circ} \mathrm{C}$ to eliminate distortions. The mean size and spacing of the precipitated particles were determined from the electron micrographs of the replica taken on the surfaces of tensile specimens. Both optical microscope and replica techniques were used to observe the slip lines.

\section{Experimental Results}

Fig. 1 shows the nominal stress versus cross-head displacement curves in Fe-10\%Mo specimens deformed at room temperature. The yield stresses in the aged specimens are lower than those in the asquenched specimen; the three groups of crystal orientation show almost the same value, indicating no perceptible dependence on crystal orientation. Another feature for the aged specimens is a very high rate of work hardening at small strains. The results for the aged and as-quenched specimens gave about 500 and $115 \mathrm{~kg} / \mathrm{mm}^{2}$ in $\partial \sigma / \partial \varepsilon$ respectively at a strain of 0.02. Table 2 illustrates the results of tensile testing for all the aged specimens investigated.

In Fig. 2 the values of $\sigma_{0}$ are plotted as a function of temperature. The values of $\sigma_{0}$ for aged Fe-7\% Mo and $\mathrm{Fe}-10 \% \mathrm{Mo}$ specimens are related to three orientations $\mathrm{A}, \mathrm{B}, \mathrm{C}$, and those for as-quenched $\mathrm{Fe}-3 \% \mathrm{Mo}$ and $\mathrm{Fe}-5 \% \mathrm{Mo}$ specimens are plotted only for orientation $A$. The temperature dependence of $\sigma_{0}$ for both groups of specimens agreed fairly well with each other.

The change in crystal orientation for the aged specimens with straining turned out to be less than 1 degree even at 10\% elongation. For the observation of slip lines, a considerable number of replica micrographs were taken on the surface of the specimens deformed at various temperatures. In the as-quenched specimens slip patterns were wavy at higher temperatures as in ordinary iron solid solution alloys and became straight with decreasing temperature. Photo. 1(a) shows a replica micrograph of the specimen, which has a crystallographic orientation of single slip, i.e. orientation A, extended $2 \%$ at room temperature. In contrast to these results, no slip lines could be revealed on the aged specimen surfaces until the elongation reached more than $6 \%$, even in cases when the orientation of tensile specimens was selected so as to glide only in a single slip system. Photo. 1(b) shows slip patterns on the surface of the aged specimens with orientation $\mathbf{A}$ extended $8 \%$ at room temperature. Compared with

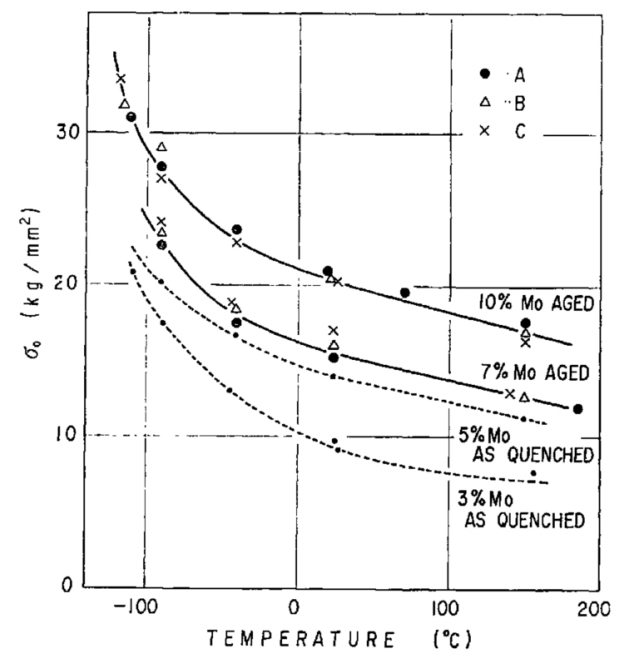

Fig. 2 Yield stress as a function of deformation temperature

Table 2 Various parameters used for evaluation of experimental results. $T_{t}$ and $\mathrm{M}_{0}^{m}$ represents the deformation temperature and molybdenum concentration in matrix after aging respectively. The meaning of other parameters are explained in the text

\begin{tabular}{|c|c|c|c|c|c|c|c|c|c|}
\hline $\begin{array}{c}\text { Mo } \\
(w t \%)\end{array}$ & $\begin{array}{c}T_{t} \\
\left({ }^{\circ} \mathrm{C}\right)\end{array}$ & $\begin{array}{c}\tau_{0} \\
\left(\mathrm{~kg} / \mathrm{mm}^{2}\right)\end{array}$ & $\begin{array}{c}\mathrm{M}_{0}^{m} \\
(\mathrm{at} \%)\end{array}$ & $f$ & $\begin{array}{c}\tau_{m} \\
\left(\mathrm{~kg} / \mathrm{mm}^{2}\right)\end{array}$ & $\begin{array}{c}N_{s} \\
\left(\times 10^{-7} \mathrm{~cm}^{-2}\right)\end{array}$ & $\begin{array}{c}r_{s} \\
\left(\times 10^{5} \mathrm{~cm}\right)\end{array}$ & $\begin{array}{c}R_{s} \\
\left(\times 10^{5} \mathrm{~cm}\right)\end{array}$ & $\begin{array}{c}b D^{-1} \\
\left(\times 10^{4} \mathrm{~cm}\right)\end{array}$ \\
\hline $\begin{array}{l}10 \\
" \\
" 7 \\
7\end{array}$ & $\begin{array}{l}150 \\
" \\
" \\
\prime \prime\end{array}$ & $\begin{array}{l}8.6 \\
8.2 \\
8.0 \\
6.2\end{array}$ & $\begin{array}{l}2.9 \\
2.4 \\
2.7 \\
2.9\end{array}$ & $\begin{array}{l}0.11 \\
0.12 \\
0.11 \\
0.043\end{array}$ & $\begin{array}{l}5.5 \\
4.7 \\
5.2 \\
5.5\end{array}$ & $\begin{array}{c}7.96 \\
10.3 \\
6.27 \\
0.74\end{array}$ & $\begin{array}{l}2.10 \\
1.92 \\
2.36 \\
4.28\end{array}$ & $\begin{array}{c}5.60 \\
4.93 \\
6.30 \\
18.3\end{array}$ & $\begin{array}{l}5.15 \\
5.86 \\
4.66 \\
1.53\end{array}$ \\
\hline $\begin{array}{l}10 \\
" \\
" 1 \\
" 7 \\
7 \\
" \\
"\end{array}$ & $\begin{array}{c}\text { R.T. } \\
" \prime \\
" \\
" \\
" \\
" \\
"\end{array}$ & $\begin{array}{r}10.2 \\
10.0 \\
10.0 \\
10.5 \\
7.5 \\
7.8 \\
8.5\end{array}$ & $\begin{array}{l}2.7 \\
2.4 \\
2.4 \\
2.9 \\
2.7 \\
2.7 \\
2.9\end{array}$ & $\begin{array}{l}0.11 \\
0.12 \\
0.12 \\
0.11 \\
0.049 \\
0.049 \\
0.043\end{array}$ & $\begin{array}{l}6.5 \\
6.0 \\
6.0 \\
6.8 \\
6.5 \\
6.4 \\
6.8\end{array}$ & $\begin{array}{c}8.98 \\
14.8 \\
4.82 \\
4.78 \\
0.58 \\
0.49 \\
0.69\end{array}$ & $\begin{array}{l}1.98 \\
1.60 \\
2.82 \\
2.70 \\
5.21 \\
5.65 \\
4.46\end{array}$ & $\begin{array}{c}5.03 \\
4.11 \\
7.25 \\
7.25 \\
20.8 \\
22.6 \\
19.1\end{array}$ & $\begin{array}{l}5.80 \\
6.58 \\
4.21 \\
4.11 \\
1.39 \\
1.30 \\
1.47\end{array}$ \\
\hline $\begin{array}{l}10 \\
" 1 \\
" 1 \\
7 \\
" \\
"\end{array}$ & $\begin{array}{c}-90 \\
n \\
n \\
n \\
n \\
n\end{array}$ & $\begin{array}{l}13.5 \\
13.8 \\
14.5 \\
11.2 \\
11.6 \\
12.0\end{array}$ & $\begin{array}{l}2.4 \\
2.9 \\
3.1 \\
2.9 \\
2.7 \\
2.4\end{array}$ & $\begin{array}{l}0.12 \\
0.11 \\
0.10 \\
0.043 \\
0.049 \\
0.058\end{array}$ & $\begin{array}{r}9.6 \\
10.3 \\
10.3 \\
10.1 \\
9.9 \\
9.6\end{array}$ & $\begin{array}{l}5.87 \\
4.65 \\
4.30 \\
0.73 \\
0.36 \\
1.02\end{array}$ & $\begin{array}{l}2.55 \\
2.74 \\
2.72 \\
4.32 \\
6.63 \\
4.26\end{array}$ & $\begin{array}{c}6.55 \\
7.33 \\
7.65 \\
16.4 \\
26.5 \\
15.7\end{array}$ & $\begin{array}{l}4.60 \\
4.07 \\
3.83 \\
1.75 \\
1.12 \\
1.85\end{array}$ \\
\hline
\end{tabular}



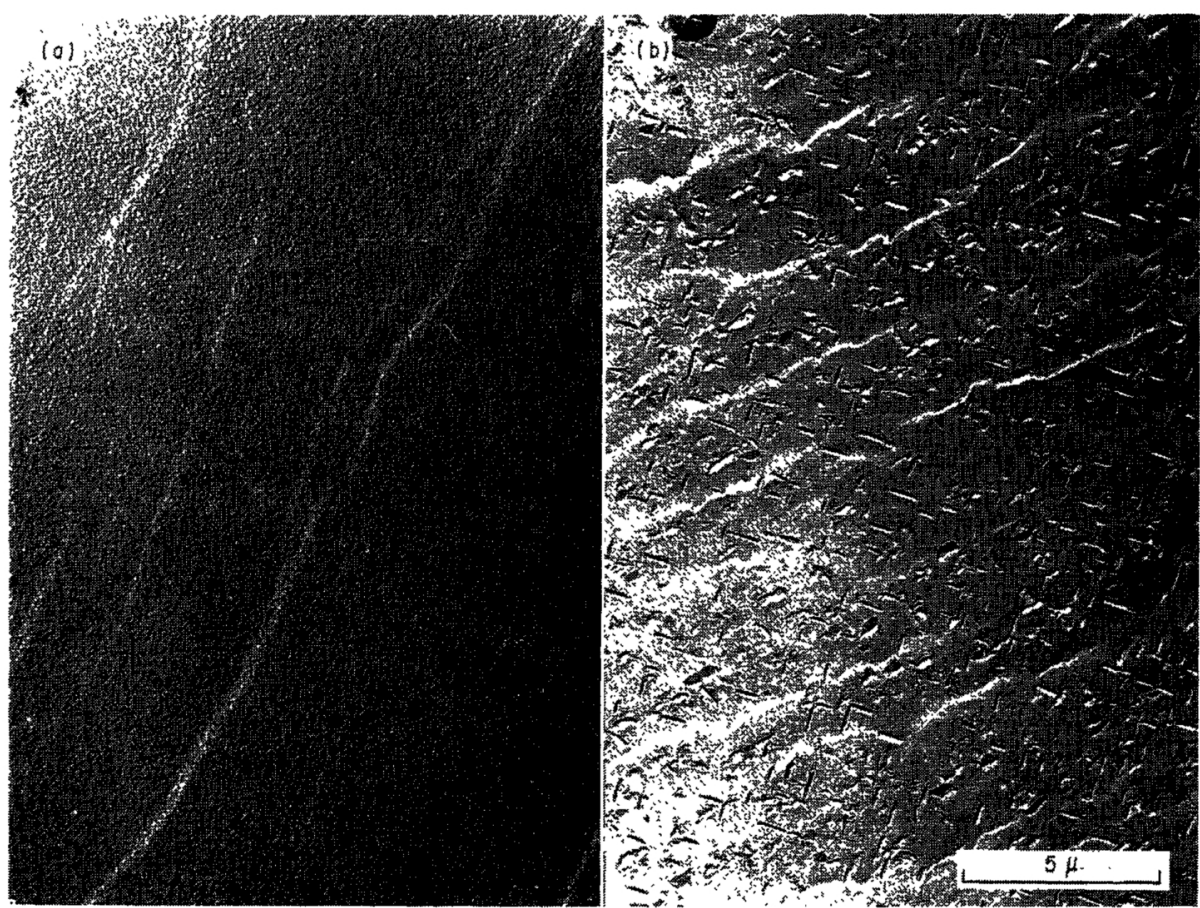

Photo. 1 Replica micrographs showing slip lines in Fe-10\%Mo specimens extended at room temperature

(a) for as-quenched specimen extended $2 \%$

(b) for specimen extended $8 \%$ after aged at $700^{\circ} \mathrm{C}$ for $40 \mathrm{hr}$

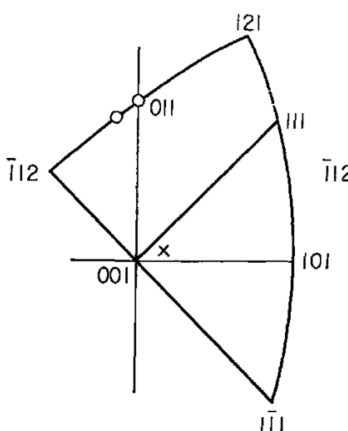

$x$ TENSILE AXIS

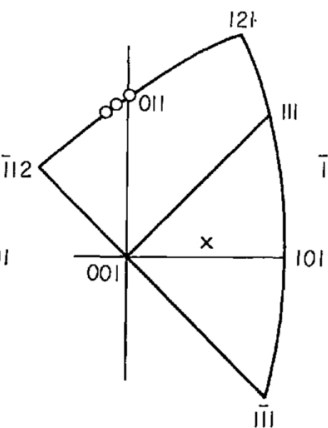

- SLIP PLANE

Fig. 3 Tensile axes and slip planes in Fe-10\%.Mo single crystal specimens extended at room temperature

those in the as-quenched specimens, short and fine primary slip lines as well as cross-slip lines over the precipitates were clearly observed, although secondary slip lines were not resolved even at this amount of extension. The general appearance of slip lines in the aged specimens did not change largely with deformation temperature at a strain of about $10 \%$. Most active primary slip planes were analyzed from the optical micrographs of the slip lines and turned out to locate near the plane which has a maximum resolved shear stress, as shown in Fig. 3.

In Fig. 4 is plotted a linear relation between lattice constants and molybdenum contents in a matrix solid solution. By measuring the lattice constant of the matrix in the aged specimen, the molybdenum content in the matrix is estimated from Fig. 4. Then, the critical resolved shear stress for the matrix, i.e. frictional stress $\tau_{m}$, is obtained from Fig. 2. Molybdenum contents in the matrix and $\tau_{m}$ are tabulated in Table 2 for all the specimens investigated, together with other parameters which are described in the following section.

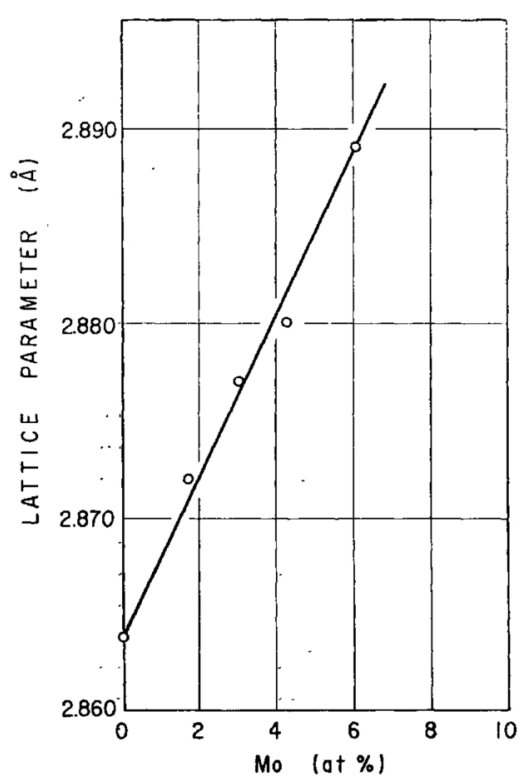

Fig. 4 Variation of lattice parameter in Fe-Mo alloys with molybdenum concentration 


\section{Discussion}

\section{Yield stress}

The yield stresses in the alloys containing nondeformable particles are expressed as a sum of the frictional stress of the matrix and that due to dispersed particles:

$$
\tau_{0}=\tau_{m}+\tau_{p} .
$$

The second term was described by Orowan as

$$
\tau_{p}=\frac{G_{m} b}{2 R_{s}},
$$

where $G_{m}$ is the shear modulus of the matrix, $2 R_{s}$ is the average interparticle spacing on a primary slip plane, and $b$ is the Burgers vector of glide dislocations in the matrix. In bcc metals and alloys the frictional stresses are, in general, larger and show stronger temperature dependence than those in fco metals. Therefore, in order to evaluate the second term in eq. (1), the first term should be appropriately estimated. In addition, in Orowan's formulation an important parameter is the interparticle spacing, $2 R_{s}$, of the dispersed particles. A considerable amount of work has been already carried out on the correct evaluation of the interparticle spacing. Recently, $\operatorname{Kocks}^{(10)}$ and Foreman et al.(11) calculated more accurately the critical shear stress in the crystal assuming a random distribution of point obstacles on a slip plane. According to their results, the critical obstacle spacing $l_{c}$ on a slip plane, corresponding to the macroscopic critical flow stress, is about $20 \%$ larger than the spacing in square array of the same obstacle density.

It is, in general, considered that in $b c c$ metals cross slips of dislocations take place more easily than in fcc metals. Therefore, in dispersion-hardened alloys with $b c c$ structures the macroscopic yield stress may be influenced by the dislocation cross-slips. As Ashby(12) stated, this mechanism might be expected to lead to a lower yield stress than the Orowan's and also a greater temperature dependence than is expected from the Orowan's theory.

On the other hand, although the dislocations bow out between the particles leaving the loops around the particles in Orowan's model, dislocation loops of this type have been observed only in few cases by transmission electron microscopy. Koda et al.(13)(14) studied the interactions between moving dislocations and particles in the precipitation-hardening aluminum alloys by means of electron microscopy: In some cases the glide dislocations bow out between the particles following the Orowan's mechanism, and in

(10) U. F. Kocks : Phil. Mag., 13 (1966), 541; Acta Met., 14 (1966), 1629.

(11) A. J. E. Forman and M. J. Makin : Phil. Mag., 13 (1966), 911; Can. J. Phys., 45 (1967), 511.

(12) M. F. Ashby : Electron Microscopy and Strength of Crystals, Interscience Publishers, New York, (1963), p. 891.

(13) M. Nemoto and S. Koda : Trans. JIM, 7 (1966), 235.

(14) S. Koda, K. Matsuura and M. Nemoto : J. ATM, 8 (1963), 197. other cases the cross-slips of dislocations take place and the dislocation loops are formed. Humphrey et al. (15) investigated the effect of dispersed particles in a low volume fraction upon the dislocation distribution in deformed copper crystals. Electron transmission microscopy of sections cut either parallel or perpendicular to the primary slip plane of deformed crystals disclosed the presence of prismatic loops caused by cross-slips of dislocations at the particles. Also, their results showed that the increment in yield stress of two-phase copper alloy over that of the single-phase crystals was approximately consistent with that of the Orowan's bowing mechanism in spite of the occurrence of cross-slips.

The calculation on the interparticle spacing has usually been made when the point-like or spherical obstacles are distributed at random or regularly. In the present Fe-Mo alloy, the shape, size and distribution of the precipitated particles were non-spherical, irregular and nonuniform as shown in Photo. 1(b). Since a method to obtain the actual interparticles spacing of the particles is not established for such a precipitated alloy system, it was forced to roughly assume a regular square array of the spherical particles with a uniform diameter on the slip plane. In this case, we obtain

$$
\begin{aligned}
& N_{s} \pi r_{s}^{2}=f, \\
& 2 R_{s}=N_{s}^{-1 / 2}=(\pi / f)^{1 / 2} \cdot r_{s},
\end{aligned}
$$

where $r_{s}, 2 R_{s}$, and $N_{s}$ are the radius of particles, the interparticle spacing arranged in square array, and the particle density in unit area of the slip plane, respectively, and $f$ is the volume fraction of particles. Since the precipitated phase in Fe-Mo alloy is identified with $\mathrm{Fe}_{2} \mathrm{Mo}$, $f$ was calculated from the difference of the molybdenum content in the matrix before and after the aging treatment. The particle density $N_{S}$ was measured from the replica-micrographs. Thus, $\tau_{p}$ was finally calculated by a modified Orowan's equation $^{(16)}$ :

$$
\begin{array}{r}
\tau_{p}=\frac{G_{m} b}{4 \pi} \frac{1}{2}\left(1+\frac{1}{1-\nu}\right) \frac{1}{R_{s}-r_{s}} \\
\times \ln \left(\frac{R_{s}-r_{s}}{b}\right) \equiv G_{m} b D^{-1}
\end{array}
$$

The values of $\tau_{0}, \tau_{m}, f, r_{s}, R_{s}$, and $b D^{-1}$ are tabulated in Table 2 for all the specimens extended at $150^{\circ} \mathrm{C}$, room temperature, and $-90^{\circ} \mathrm{C}$. Since values of $7_{m}$ at each deformation temperature, irrespective of molybdenum contents in the alloys investigated, could be regarded as almost constant, $\tau_{0}$ instead of $\tau_{p}$ was plotted against $b D^{-1}$. Fig. 5 shows that $\tau_{0}$ is correlated with $b D^{-1}$ approximately linearly for each deformation temperature. The shear moduli $G_{m}$ obtained from these linear relationships were $9300 \mathrm{~kg} / \mathrm{mm}^{2}$ at $-90^{\circ} \mathrm{C}, 6700$ $\mathrm{kg} / \mathrm{mm}^{2}$ at room temperature, and $6000 \mathrm{~kg} / \mathrm{mm}^{2}$ at $150^{\circ}$ C. In $b c c$ lattice the shear modulus $G$ along the [111]

(15) F. J. Humphreys and J. W. Martin : Phil. Mag., 16 (1967), 927.

(16) A. Kelly and R. B. Nicholson : Progr. Mater. Sci., 10 (1963), 151. 
crystallographic direction is expressed as $1 / 3\left(C_{11}-C_{12}\right.$ $\left.+C_{44}\right)$. The shear modulus $G_{s}$ in the iron single crystal calculated from the result by Lord et al.(17) were $7550 \mathrm{~kg} / \mathrm{mm}^{2}$ at $-196^{\circ} \mathrm{C}$ and $7250 \mathrm{~kg} / \mathrm{mm}^{2}$ at room temperature, whereas $G^{p}$ in polycrystalline iron are reported to be $8500 \mathrm{~kg} / \mathrm{mm}^{2}$ at $-100^{\circ} \mathrm{C}$ and $7800 \mathrm{~kg} /$ $\mathrm{mm}^{2}$ at room temperature. More recently, for the single crystal of $\mathrm{Fe}-3$ wt\% Mo alloy $G^{s}=6960 \mathrm{~kg} / \mathrm{mm}^{2}$ was obtained at room temperature in our laboratory ${ }^{(18)}$. The value of $G_{m}$ and its temperature dependence obtained from the present work are in good agreement with the above results. Thus, it may be concluded that the macroscopic yield stresses in this alloy system containing a high volume fraction of precipitates are properly described by the Orowan's mechanism. However, it is still uncertain whether or not the dislocation cross-slips over the distance of the particle size occur at the initial stage of small plastic strain.

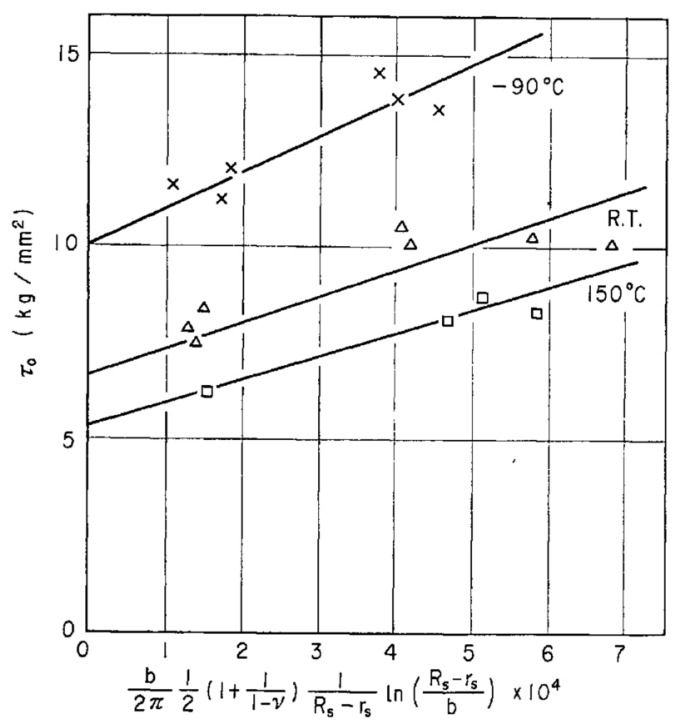

Fig. 5 Yield stress in the aged specimens deformed at temperatures of $-90^{\circ} \mathrm{C}, \mathrm{R}$. T. and $150^{\circ} \mathrm{C}$ as a function of $\frac{b}{2 \pi} \frac{1}{2}\left(1+\frac{1}{1-\nu}\right) \frac{1}{R_{s}-r_{s}} \ln \left(\frac{R_{s}-r_{s}}{b}\right)$

\section{Work hardening}

Theories on the work hardering of a dispersion hardened alloy have been proposed by Fisher et al. (5) and Ashby(6). Fisher et al. considered that the increment of strain hardening over that of the matrix without dispersed particles can be ascribed to dislocation loops left around the particles, without considering any cross-slips of moving dislocations. The loops encircling the particles exert a shear stress on the surrounding slip plane and obstruct further slip. They calculated this back stress and obtained the following relation:

$$
\Delta \tau_{h}=c f^{3 / 2} N G_{m} b r^{-1}
$$

where $f$ is a volume fraction of dispersed particles, $N$ is the number of concentric loops around each particle which cuts the glide plane in a cricle of radius $r$. How-

(17) A. E. Lord, Jr. and D. N. Beshers : J. Appl. Phys., 36 (1965), 1620.

(18) S. Takeuchi : to be published. ever, their theory contradicts with some of the recent experimental results ${ }^{(14)}$.

On the other hand, according to the work hardening theory proposed by Ashby, (a secondary slip theory), at a large strain the secondary slips take place locally around each particle, and thereafter the amount and extent of secondary slip increases with strain. In his model the secondary slip can be produced by prismatic loops punched out to relax the large plastic stress around each particle. These secondary prismatic loops interact with the glide dislocations in the primary slip system. Thus, he deduced the following equation as a stress increment $\Delta \tau_{h}$ in the parabolic stage of the stress-strain curve:

$$
\Delta \tau_{h}=K G_{m}\left(\frac{f b \varepsilon}{2 r_{s}}\right)^{1 / 2}
$$

where $2 r_{s}$ is the particle diameter and $\varepsilon$ is the shear strain. The precise mechanism by which secondary dislocations obstruct primary ones changes only the constant $K$; reasonable values for $K$ are between 0.2 and 0.4 for $f c c$ metals. Experimentally, Ebeling and Ashby showed that copper single crystals containing spherical silica particles exhibited parabolic stressstrain curves between 4 and $60 \%$ shear strains and their work hardening depended on the volume fraction $f$ and the radius of particle $r_{s}$ as given in eq. (6). To fit with their experimental results, the value of $0.24 \pm$

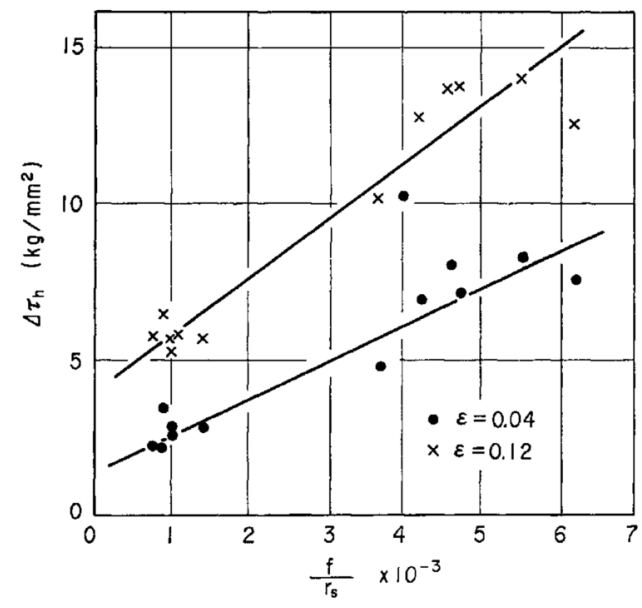

Fig. 6 Variation of the increment of flow stress at strains of $4 \%$ and $12 \%$ with $f / r_{s}$

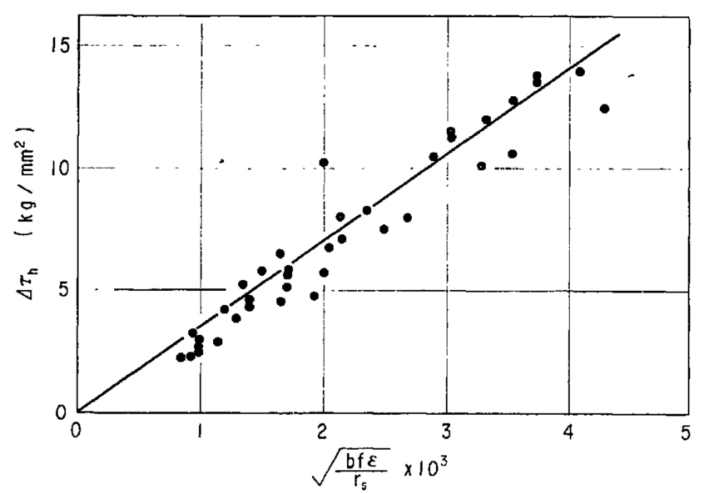

Fig. 7 Variation of the increment of flow stress at strains of $4 \%, 8 \%$ and $12 \%$ with $\left(b f \varepsilon / r_{s}\right)^{1 / 2}$. The slope of straight line gives $K G_{m}=4.9 \times 10^{8} \mathrm{~kg} / \mathrm{mm}^{2}$ 
0.04 was chosen as the value of $K$. For the present case of $\mathrm{Fe}-\mathrm{Mo}$ single crystals the increase in flow stress $\Delta \tau_{h}$ was plotted according to the above two models, as shown in Figs. 6 and 7. In Fig. 6 the values of $\Delta \tau$ are plotted against $f / r$ instead of $f^{3 / 2} / r$, because DewHughes and Robertson obtained a better linear relation for the $f / r$ plot than for $f^{3 / 2} / r$ with a slight correction of the distance between particles and dislocation sources. The results obtained were in better agreement with the Ashby's theory than that of Fisher et al., giving $K \simeq 0.70$ in contrast to 0.24 in the dispersed copper single crystals.

Furthermore, since in the present work the rotation of crystallographic orientation of the specimens with extension was less than $1^{\circ}$ even at $10 \%$ strain, it is certain that a large amount of slip must have taken place in the secondary systems. In order to confirm the existence of dislocation cross-slips at the initial stage of plastic deformation and to establish a more reliable mechanism of dislocation interactions between the primary and secondary systems, research by transmission electron microscopy is now in progress on the precipitated Fe-Mo alloys.

\section{Acknowledgments}

The authors would like to thank Mr. S. Takeuchi for his valuable discussions and advices. Thanks are also due to the other staff members in the Metal Physics Division of N.R.I.M. for their stimulating discussions. 